\title{
CREATING CONDITIONS
}

\section{Dear Reader,}

the electrification of the powertrain is by far the most dominant topic in vehicle development. It is also necessary. It therefore goes without saying that the current issue of ATZ addresses this subject in detail in its leading articles. It is not only a matter of what is technically feasible but also what makes economic sense and whether customers will want and accept it. Past editorials have already discussed at length the question of what proportion of regenerative energy in the electricity mix will mean that nationwide electric mobility makes sense from an ecological perspective. It is at least just as important to arouse customers' interest in electric cars and to reassure them regarding the reliability of this new technology and how easy it is to diagnose and repair faults.

Essentially, the industry is at the same point as it was when hybrid technology was launched onto the market a few years ago. It comes as no surprise, therefore, that the number of people who actually own an electric car at the moment is negligibly small. BMW is focusing on the subject of technology marketing, while ika is specifically targeting customer requirements.

The important question - not only from a customer's point of view - of how faults can be reliably detected and remedied and how appropriate checks can be carried out, for example as part of the vehicle's regular technical inspection, is certainly one of the first reasons. In a large-scale study, the VdTÜV, the association representing Germany's technical inspection bodies, is working on the necessary regulations for the required functional tests for the plugs, charging connectors, cables and above all batteries of electric vehicles. The aim of the study, which is scheduled to run until 2016, is to establish high-voltage guidelines for the periodic technical inspections of electric vehicles to create the necessary framework conditions for customers, vehicle inspectors and manufacturers.

A second important point is the necessary infrastructure. Many potential purchasers of electric cars do not have their own charging facility. For that reason, if local authorities, cities and companies do not make vigorous efforts to address this problem, electric mobility will remain a marginal phenomenon. Wherever you look, there is a lack of comprehensive concepts for parking and traffic guidance. If the will to promote electric mobility is to be more than mere lip service, fast and sustainable action is required. We must at last create the framework conditions that will make the sustainable introduction of electric mobility possible at all.

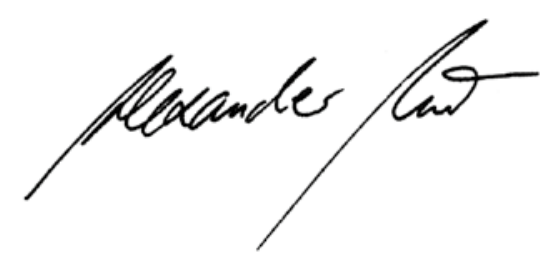

DR. ALEXANDER HEINTZEL, Editor in Chief Wiesbaden, 25 September 2014

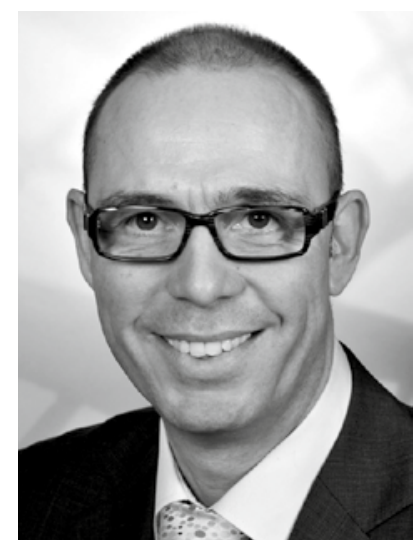

